\title{
Catalyst-Free Synthesis of Oligoanilines and Polyaniline Nanofibers Using $\mathrm{H}_{2} \mathrm{O}_{2}$
}

\author{
Sumedh P. Surwade, Srikanth Rao Agnihotra, Vineet Dua, Neha Manohar, Sujit Jain, \\ Srikanth Ammu, and Sanjeev K. Manohar* \\ Department of Chemical Engineering, University of Massachusetts Lowell, Lowell, Massachusetts 01854 \\ Received June 18, 2009; E-mail: sanjeev_manohar@uml.edu
}

Bulk quantities of polyaniline nanofibers and oligoanilines of controlled molecular weight, e.g., aniline tetramer, octamer, and hexadecamer, are obtained in one step using a simple and versatile high ionic strength aqueous system $(\mathrm{HCl} / \mathrm{NaCl})$ that permits the use of pure $\mathrm{H}_{2} \mathrm{O}_{2}$ as a mild oxidant. Polyaniline nanofibers are highly conducting, $\sigma \sim 1-5 \mathrm{~S} / \mathrm{cm}$, and spectroscopically similar to conventional polyaniline synthesized using stronger oxidants. Solution cast films of oligoanilines on flexible plastic substrates are used as chemiresistors to reversibly detect chemically aggressive vapors like $\mathrm{NO}_{2}$ in the $100-5 \mathrm{ppm}$ concentration range in ambient air.

Polyaniline is typically synthesized by oxidative polymerization of aniline in dilute acids using peroxydisulfate oxidant using a variety of approaches. ${ }^{1}$ The reaction is characterized by an induction period followed by bulk precipitation of a dark-green electrically conducting powder called emeraldine salt. Nanofibers can be obtained by altering the reaction conditions during the induction period using a variety of methods. ${ }^{2}$ There are many recent attempts to synthesize polyaniline using milder oxidizing agents, e.g., benzoyl peroxide and metal/enzyme catalyzed $\mathrm{H}_{2} \mathrm{O}_{2} \cdot{ }^{3}$ Although nanofibers have been obtained in some $\mathrm{Fe}^{2+} / \mathrm{H}_{2} \mathrm{O}_{2}$ systems, ${ }^{3 \mathrm{f}}$ in many instances there is loss of nanofiber morphology and a significant reduction in bulk conductivity as a result of defects introduced along the polymer backbone $\left(\sim 10^{-2} \mathrm{~S} / \mathrm{cm}\right) .{ }^{3}$ Pure $\mathrm{H}_{2} \mathrm{O}_{2}$ is considered to be too weak to oxidatively polymerize aniline to polyaniline; i.e., at room temperature there is no observable reaction, and at higher temperatures the reaction yields a dark brown insulating solid. In this study, we demonstrate that by simply carrying out the reaction at high ionic strength, $\mathrm{H}_{2} \mathrm{O}_{2}$ can be used as an effective oxidant to achieve the desired linear head-to-tail coupling of aniline units resulting in polyaniline that is not only highly conducting but also composed entirely of a nonwoven mesh of nanofibers. Importantly, the high ionic strength system is used to synthesize oligoanilines having preselected molecular weights that show very interesting sensor properties.

Polyaniline nanofibers are synthesized using the $\mathrm{H}_{2} \mathrm{O}_{2} / \mathrm{HCl} /$ $\mathrm{NaCl}$ system by adding $2.0 \mathrm{~mL}$ of aniline to $100 \mathrm{~mL}$ of aqueous $1.0 \mathrm{M} \mathrm{HCl}$ saturated with $\mathrm{NaCl}$ followed by addition of $5.0 \mathrm{~mL}$ of aqueous $35 \mathrm{wt} \% \mathrm{H}_{2} \mathrm{O}_{2}$. The reaction is initiated by heating gently to $\sim 50{ }^{\circ} \mathrm{C}$ and cooling to room temperature (see Supporting Information (SI) for details). After $\sim 2 \mathrm{~h}$ the dark green emeraldine salt $(\sim 200 \mathrm{mg})$ is filtered, washed, and dried under dynamic vacuum $\left(\sigma_{\mathrm{RT}} \sim 1-5 \mathrm{~S} / \mathrm{cm}\right.$, pressed pellet $)$.

The scanning electron microscopy (SEM) image of the darkgreen emeraldine salt shows that it is composed entirely of micrometers long, 60-80 nm diameter nanofibers (Figure 1A). Nanofibers are obtained without the aid of added seed fibers, oligomers, and other templates, and even when the ionic strength is high. We have recently shown that nanofiber formation in polyaniline is governed by aniline dimer formation on inert surfaces,

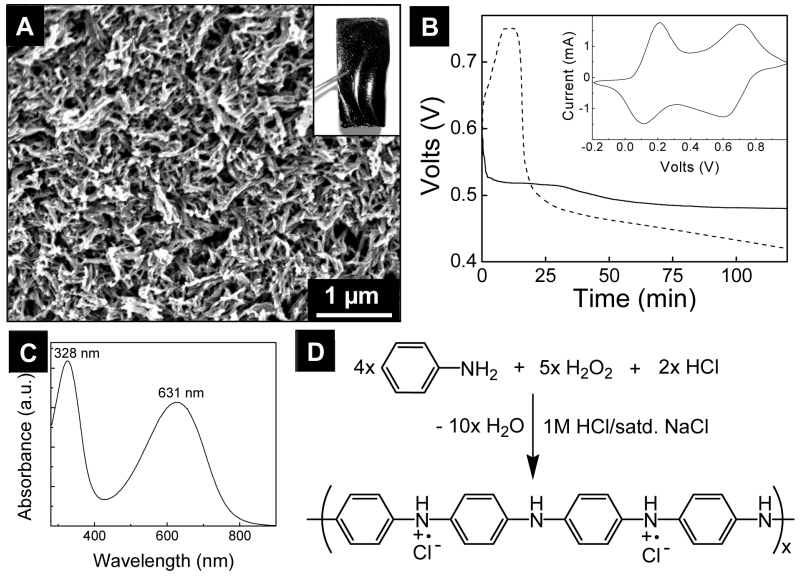

Figure 1. Polyaniline synthesized using the $\mathrm{H}_{2} \mathrm{O}_{2} / \mathrm{HCl} / \mathrm{NaCl}$ system: (A) SEM image of as-synthesized polyaniline nanofibers. Inset: Free-standing film of emeraldine base cast from solution in NMP. (B) Potential-time profile of aniline polymerization using $\mathrm{H}_{2} \mathrm{O}_{2}$ (solid line) and $\left(\mathrm{NH}_{4}\right)_{2} \mathrm{~S}_{2} \mathrm{O}_{8}$ (dotted line). Inset: Cyclic voltammogram in aq. $1.0 \mathrm{M} \mathrm{HCl}, \mathrm{SCE}$ reference. (C) UV-vis spectrum in NMP solvent. (D) Reaction scheme.

such as the walls of the reaction flask, etc. ${ }^{4}$ Under the right conditions, aniline dimer spontaneously dimerizes to aniline tetramer nanofibers that subsequently act as seeds that promote bulk nanofiber formation. We believe the high ionic strength in the $\mathrm{H}_{2} \mathrm{O}_{2}$ / $\mathrm{HCl} / \mathrm{NaCl}$ system favors ionic over free radical pathways, e.g., radical cation coupling (head-to-tail) to yield aniline dimer over free radical pathways that would yield undesired low molecular weight products. Suppressing free radical pathways is particularly important when employing $\mathrm{H}_{2} \mathrm{O}_{2}$ because of the myriad pathways available that would not yield polyaniline. Therefore, the high ionic strength in the reaction simultaneously promotes linear chain growth and fibrillar morphology while eliminating the need for added catalysts to activate $\mathrm{H}_{2} \mathrm{O}_{2}$.

Potential-time profiling shows that the $\mathrm{H}_{2} \mathrm{O}_{2} / \mathrm{HCl} / \mathrm{NaCl}$ system does not proceed via the intermediacy of polyaniline in the highly oxidized pernigraniline oxidation state that is typical of the classical $\mathrm{S}_{2} \mathrm{O}_{8}{ }^{2-}$ system (Figure 1B). ${ }^{1 \mathrm{~b}}$ The gradual fall in potential during the course of the reaction suggests that only the chain ends are oxidized and couple with new aniline units while the main chain remains in the half-oxidized emeraldine oxidation state. ${ }^{3 \mathrm{~b}}$ The new polyaniline is spectroscopically and electrochemically similar to conventional polyaniline (Figure 1C, SI). Free-standing films ( $\sigma \sim 1 \mathrm{~S} / \mathrm{cm}$ after $\mathrm{HCl}$ doping) are readily obtained from NMP solutions which can be made more robust when a small amount of epoxidized linseed oil is used as a biodegradable plasticizer (Figure $1 \mathrm{~A}$, inset).

The $\mathrm{H}_{2} \mathrm{O}_{2} / \mathrm{HCl} / \mathrm{NaCl}$ system can also be used to synthesize aniline tetramer, octamer, and hexadecamer (Figure 2). For example, when 

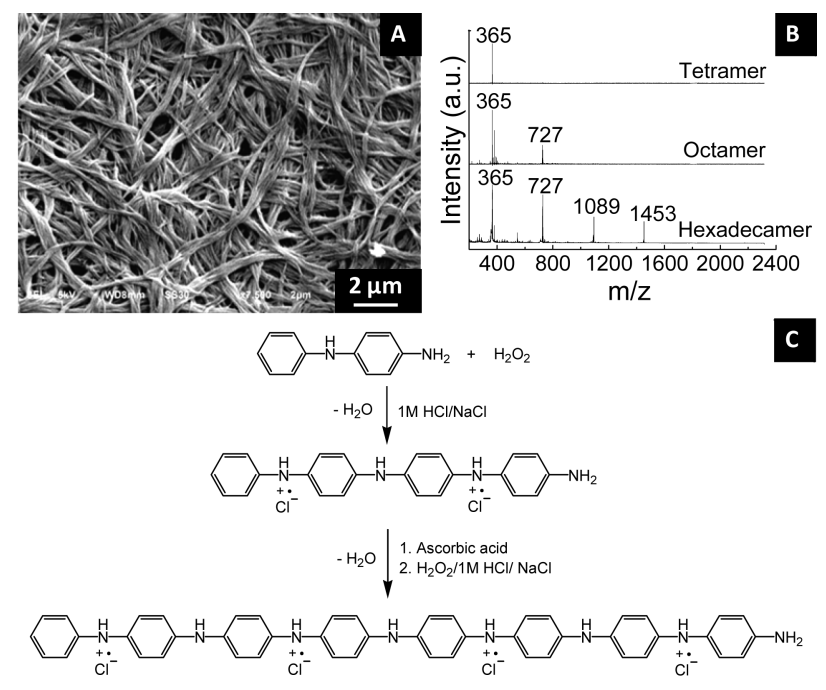

C

Figure 2. Aniline oligomers synthesized using $\mathrm{H}_{2} \mathrm{O}_{2} / \mathrm{HCl} / \mathrm{NaCl}$ system: (A) SEM image of aniline tetramer nanofibers synthesized from aniline dimer. (B) MALDI-TOF mass spectrometry; see SI for fragmentation pattern. (C) Reaction scheme (tetramer and octamer only).

an insoluble aniline dimer is added to the above system a spontaneous reaction occurs resulting in the formation of micrometers long nanofibers of aniline tetramer in the emeraldine oxidation state $\left(\sigma \sim 10^{-2} \mathrm{~S} / \mathrm{cm}\right)$. We have recently reported this unusual solidstate reaction in the aniline $/ \mathrm{S}_{2} \mathrm{O}_{8}{ }^{2-}$ system and believe this to be the key to bulk nanofiber formation. ${ }^{4}$ The reaction stops at the tetramer stage but can be extended to the octamer stage by reducing aniline tetramer to the leucoemeraldine oxidation state using ascorbic acid and repeating the reaction (Figure 2, scheme). Aniline octamer is the sole product and is easily isolated $\left(\sigma \sim 10^{-2} \mathrm{~S} / \mathrm{cm}\right)$. This is a solid-state reaction that takes place in an aqueous dispersion and is unusual in that tetramer units have to couple specifically at the chain ends which requires a significant degree of chain mobility. It is unclear at the present time how this occurs, although we could not extend the reaction to the hexadecamer suggesting that chain mobility is too low at the octamer stage. Surprisingly, aniline hexadecamer is the sole product when a 1:10 mixture of aniline tetramer and aniline monomer is added to the $\mathrm{H}_{2} \mathrm{O}_{2} / \mathrm{HCl} / \mathrm{NaCl}$ system indicative of the versatility of the system (see SI). It is to be noted that aniline oligomers have been obtained using $\mathrm{FeCl}_{3} / \mathrm{HCl}$ and $\mathrm{S}_{2} \mathrm{O}_{8}{ }^{2-} / \mathrm{HCl},{ }^{5}$ and the present study highlights the use of $\mathrm{H}_{2} \mathrm{O}_{2} / \mathrm{HCl} / \mathrm{NaCl}$ as an environmentally friendly, mild, and highly versatile oxidizing system that can be used to affect a variety of transformations.

Aniline oligomers synthesized previously have been used to detect a variety of common organic vapors; e.g., chemiresistor films of aniline octamer were shown to be very sensitive to toluene, $\mathrm{CHCl}_{3}$, etc. ${ }^{6}$ However, there are no reports using oligoanilines to detect chemically aggressive and highly oxidizing vapors like $\mathrm{NO}_{2}$, $\mathrm{Cl}_{2}$, etc. This could be because corresponding sensors made of films of polyaniline, polypyrrole, etc. typically show an irreversible resistance change when exposed to these vapors, a behavior that is rationalized in terms of oxidation or covalent bond formation. ${ }^{7}$ This is not the case for oligoanilines.

For example, films of aniline tetramer, octamer, and hexadecamer drop-cast on flexible, plastic substrates show a sharp increase in resistance when exposed to $\mathrm{NO}_{2}$ vapor in the $100-5 \mathrm{ppm}$ concentration range. Although the signal does not reverse spontaneously when the sensor is removed from the test chamber, the resistance recovers readily to the original baseline value when
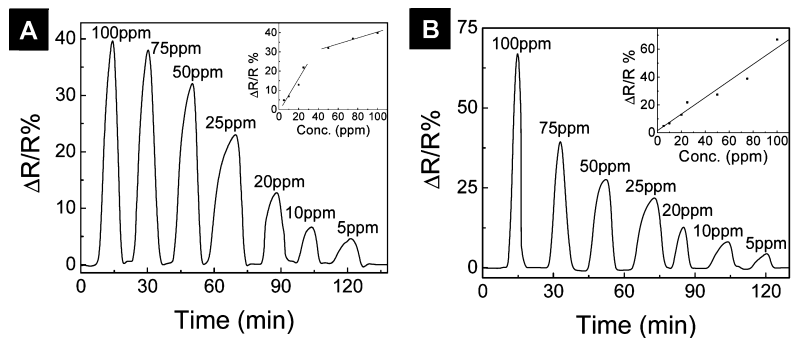

Figure 3. Plot of percent change in resistance vs time of (A) aniline octamer and (B) aniline hexadecamer, when exposed to $\mathrm{NO}_{2}$ vapor $\left(\mathrm{N}_{2}\right.$ carrier gas). Vapor concn values indicated at the troughs. Insets: corresponding plots of percent change in resistance vs vapor concn.

irradiated using a $254 \mathrm{~nm}$ UV light source (Figure 3). Oligoaniline films synthesized previously using other oxidants behave similarly. The fairly high detection limit ( $>5 \mathrm{ppm})$ and the difference in sensor response between octa- and hexadecaaniline described in Figure 3 could be because film thickness and geometry are not optimized (see SI). Although $\mathrm{NO}_{2}$ vapor is highly reactive and would be expected to oxidize (and/or degrade) thin oligoaniline films, it is clear that this is not taking place in the time frame of our sensor experiments; e.g., there is no change in the UV-vis spectra before and after a series of vapor exposure/UV irradiation cycles (SI). The resistance change is irreversible without UV irradiation suggesting that $\mathrm{NO}_{2}$ vapor is strongly physisorbed on the film and could irreversibly react with the oligoaniline backbone if given sufficient time.

In summary, we demonstrate for the first time (i) a one-step synthesis of bulk quantities of polyaniline nanofibers using $\mathrm{H}_{2} \mathrm{O}_{2}$ oxidant without added catalysts; (ii) a one-step synthesis of oligoanilines of controlled molecular weight using $\mathrm{H}_{2} \mathrm{O}_{2}$; (iii) a versatile, aqueous high ionic strength system $(\mathrm{HCl} / \mathrm{NaCl})$ that permits the use of $\mathrm{H}_{2} \mathrm{O}_{2}$ as a mild oxidant; and (iv) chemiresistors made of thin oligoaniline films drop-cast on rugged and flexible plastic substrates to reversibly detect $\mathrm{NO}_{2}$ vapor.

Acknowledgment. Funding from the UMass Lowell, MTCfunded NCOE, and NSF-funded CHN, NSF Award No. 0425826.

Supporting Information Available: Synthesis procedure, characterization (UV-vis, FTIR, NMR, aq. electrochemistry), sensor fabrication. This material is available free of charge via the Internet at http:// pubs.acs.org.

\section{References}

(1) MacDiarmid, A. G. Prix Nobel 2001, 191-211.

(2) (a) Li, W.; Wang, H.-L. J. Am. Chem. Soc. 2004, 126, 2278-2279. (b) Zhang, X.; Goux, W. J.; Manohar, S. K. J. Am. Chem. Soc. 2004, 126, 4502-4503. (c) Li, D.; Huang, J.; Kaner, R. B. Acc. Chem. Res. 2009, 42, 135-145. (d) Li, G.; Peng, H.; Wang, Y.; Qin, Y.; Cui, Z.; Zhang, Z. Macromol. Rapid Commun. 2004, 25, 1611-1614. (e) Chiou, N.-R.; Epstein, A. J. Adv. Mater. 2005, 17, 1679-1683.

(3) (a) Sai Ram, M.; Palaniappan, S. J. Mol. Catal. 2003, 201, 289-296. (b) Sun, Z.; Geng, Y.; Li, J.; Wang, X.; Jing, X.; Wang, F. J. Appl. Polym. Sci. 1999, 72, 1077-1084. (c) Liu, W.; Kumar, J.; Tripathy, S.; Senecal, K. J.; Samuelson, L. J. Am. Chem. Soc. 1999, 121, 71-78. (d) Moon, D. K.; Osakada, K. Maruyama, T. Yamamoto, T. Makromol Chem. 1992, 193, 1723-1728. (e) Dias, H. V. R.; Wang, X.; Rajapakse, R. M. G.; Elsenbaumer, R. L. Chem. Commun. 2006, 976-978. (f) Wang, Y.; Jing, X.; Kong, J. Synth. Met. 2007, 157, 269-275.

(4) Surwade, S. P.; Manohar, N.; Manohar, S. K. Macromolecules 2009, 42, 1792-1795.

(5) (a) Zhang, W. J.; Feng, J.; MacDiarmid, A. G.; Epstein, A. J. Synth. Met. 1997, 84, 119-120. (b) Wei, Z.; Faul, C. F. J. Macromol. Rapid Commun. 2008, 29, 280-292.

(6) Feng, J.; MacDiarmid, A. G. Synth. Met. 1999, 102, 1304-1305.

(7) (a) Sadek, A.; Wlodarski, Z.; Shin, W. K.; Kaner, R. B.; Kalantar-zadeh, K. Nanotechnology 2006, 17, 4488-4492. (b) Yan, X. B.; Han, Z. J.; Yang, Y.; Tay, B. K. Sens. Actuators B 2007, B123, 107-113.

JA905014E 